\title{
The Effect of Nilvadipine, a Dihydropyridine Type Calcium Channel Blocker, on Local Cerebral Blood Flow in Rats
}

\author{
Yasuhisa Furuichi, Shoji Takakura, Hisashi Satoh, \\ Jo Mori and Masanobu Kohsaka \\ Department of Pharmacology, Product Development Laboratories, Fujisawa Pharmaceutical Co., Ltd., \\ 2-1-6 Kashima, Yodogawa-ku, Osaka 532, Japan
}

Received October 18, 1991 Accepted February 10, 1992

\begin{abstract}
The effect of nilvadipine, a dihydropyridine type calcium channel blocker, on local cerebral blood flow ( $1 \mathrm{CBF}$ ) was investigated using the autoradiographic iodo $\left[{ }^{14} \mathrm{C}\right]$ antipyrine technique in rats. In control rats, ICBF in cortical areas and in the superior colliculus and inferior colliculus was higher than that in the hippocampus, septal nucleus, globus pallidus and substantia nigra. Nilvadipine ( $32 \mu \mathrm{g} / \mathrm{kg}$, i.v.) increased ICBF in all structures (significantly in 11 of 21 structures) in spite of a $33 \%$ reduction in mean arterial blood pressure. These results confirm that nilvadipine has the ability to increase cerebral blood flow.
\end{abstract}

Calcium antagonists have been mainly used clinically as antihypertensive drugs. These drugs exert their vasodilatory effects by blocking $\mathrm{Ca}$ channels on the vascular smooth muscle cell membranes (1). Recently, some of these drugs have been tested in the chronic phase of brain infarctions, because of their effect on the cerebral circulation $(2,3)$.

Nilvadipine (a 1,4-dihydropyridine derivative) is a calcium channel blocker that is already used clinically as an antihypertensive drug. Nilvadipine has selective and long-lasting effects on both cerebral and coronary arteries (4).

However, the effect of nilvadipine on cerebral blood flow (CBF) in intact animals has not been clearly established because previous studies have only indirectly ascertained CBF by measuring blood flow in major arteries running into the brain. The present study was carried out to clarify the direct effects of nilvadipine on local cerebral blood flow (ICBF) using an in vivo autoradiographic technique in rats.

Experiments were performed on 8-10 week old male Wistar rats (Japan SLC). Rats were freely given food and water until the day of the experiment. The ICBF was measured using the autoradiographic technique with iodo$\left[{ }^{14} \mathrm{C}\right]$ antipyrine as the tracer (5). The animals were lightly anesthetised with urethane $(500 \mathrm{mg} / \mathrm{kg}$, i.p.). A small incision was made in the groin, and the femoral vessels were exposed. Polyethylene catheters filled with heparinized saline were inserted into the femoral artery and vein for measurement of arterial blood pressure, sampling of arterial blood and administration of drugs and the tracer. Nilvadipine $(32 \mu \mathrm{g} / 0.5 \mathrm{ml} / \mathrm{kg})$ or polyethylene glycol 400 (PEG-400), the vehicle, was given as an intravenous injection over 1 min through the femoral vein. The tracer infusion was started $15 \mathrm{~min}$ after the administration of the drugs. Iodo $\left[{ }^{14} \mathrm{C}\right]$ antipyrine $(20 \mu \mathrm{Ci} / 0.8 \mathrm{ml} / \mathrm{rat}$, $58.3 \mathrm{mCi} / \mathrm{mmol}$ ) was infused into the femoral 
vein over a 40 -sec period with a peristaltic pump. During infusion of the tracer, 10 blood samples $(20 \mu \mathrm{l})$ were collected from the femoral arterial catheter. At the end of tracer infusion, the animals were decapitated immediately. Thereafter, the brains were quickly dissected out and frozen in dry-ice powder. One milliliter of solubilizer (Amersham) and hydrogen peroxide $(0.2 \mathrm{ml})$ were added to bleach the blood and to extract the radioisotope. After that, eight milliliters of liquid scintillant (Aquasol 2, Amersham) was added, and liquid scintillation analysis was performed. Brains were sectioned in a cryostat at $-20^{\circ} \mathrm{C}$. The $20-\mu \mathrm{m}$ slices were mounted on glass cover slips and dried on a hot plate. Autoradiograms were prepared from these sections together with ${ }^{14} \mathrm{C}$-methylacrylate standards (Amersham) by applying them to X-ray film (Kodak NMC-100) for 14 days in light-tight cassettes. Local cerebral blood flow was calculated in 21 structures defined in a rat brain atlas (6), from the time course of iodo $\left[{ }^{14} \mathrm{C}\right]$ antipyrine in arterial blood and the ${ }^{14} \mathrm{C}$ concentration in cerebral tissue, using an image analyzing system, "MCID" (Imaging Research Inc.). Physiological variables were measured with a blood gas analyzer (CIBA CORNING 288) using 150- $\mu$ l blood samples taken from the femoral arterial catheter before and $15 \mathrm{~min}$ after drug administration. Body temperature was kept at about $37^{\circ} \mathrm{C}$ using a heating mat.

The physiological variables are shown in Table 1. There were no significant changes in arterial carbon dioxide tension $\left(\mathrm{PCO}_{2}\right)$, arterial oxygen tension $\left(\mathrm{PO}_{2}\right), \mathrm{pH}$ and hematocrit following drug administration. Nilvadipine (32 $\mu \mathrm{g} / \mathrm{kg}$, i.v.) reduced the MABP by $33 \%$, while PEG-400 (vehicle) had no effect.

The ICBF is shown in Fig. 1. In the control rats, which were given PEG-400, the ICBF varied between brain structures. The blood flow in the frontal cortex $(144.8 \mathrm{ml} / 100$ $\mathrm{g} / \mathrm{min})$, parietal cortex $(143.7 \mathrm{ml} / 100 \mathrm{~g} / \mathrm{min})$, cingulate cortex $(148.2 \mathrm{ml} / 100 \mathrm{~g} / \mathrm{min})$, superior colliculus $(131.1 \mathrm{ml} / 100 \mathrm{~g} / \mathrm{min})$ and inferior colliculus $(173.7 \mathrm{ml} / 100 \mathrm{~g} / \mathrm{min})$ was higher than that in the globus pallidus $(77.5$ $\mathrm{ml} / 100 \mathrm{~g} / \mathrm{min})$, hippocampus $(75.2 \mathrm{ml} / 100$ $\mathrm{g} / \mathrm{min})$, septal nucleus $(89.6 \mathrm{ml} / 100 \mathrm{~g} / \mathrm{min})$ and substantia nigra $(91.7 \mathrm{ml} / 100 \mathrm{~g} / \mathrm{min})$. When nilvadipine was administered intravenously, ICBF was increased in all structures (significant in 11 of the 21 structures that were measured). Nilvadipine caused a greater increase in the blood flow in the frontal, pari-

Table 1. Physiological variables of rats after administration of nilvadipine $(32 \mu \mathrm{g} / \mathrm{kg}$, i.v. $)$

\begin{tabular}{llcc}
\hline & \multicolumn{1}{c}{ Variables } & Baseline & After $15 \mathrm{~min}$ \\
\hline & $\mathrm{MABP}(\mathrm{mmHg})$ & $127.7 \pm 3.2$ & $125.5 \pm 4.1$ \\
& $\mathrm{PO}_{2}(\mathrm{mmHg})$ & $40.3 \pm 0.7$ & $40.7 \pm 1.2$ \\
Vehicle & $\mathrm{PCO}_{2}(\mathrm{mmHg})$ & $97.8 \pm 1.7$ & $106.0 \pm 5.1$ \\
$(\mathrm{n}=11)$ & $\mathrm{pH}$ & $7.385 \pm 0.004$ & $7.382 \pm 0.006$ \\
& $\mathrm{Hct}(\%)$ & $58.0 \pm 0.7$ & $56.5 \pm 0.7$ \\
& $\mathrm{MABP}(\mathrm{mmHg})$ & $122.1 \pm 3.2$ & $84.1 \pm 4.1$ \\
& $\mathrm{PO}_{2}(\mathrm{mmHg})$ & $40.4 \pm 0.9$ & $39.7 \pm 0.8$ \\
& $\mathrm{PCO}_{2}(\mathrm{mmHg})$ & $102.5 \pm 4.1$ & $106.3 \pm 3.9$ \\
Nilvadipine & $\mathrm{pH}$ & $7.387 \pm 0.004$ & $7.374 \pm 0.005$ \\
$(\mathrm{n}=11)$ & $\mathrm{Hct}(\%)$ & $56.6 \pm 1.2$ & $54.6 \pm 1.0$ \\
& &
\end{tabular}

Data are means \pm S.E. of 11 experiments. MABP, mean arterial blood pressure; $\mathrm{PO}_{2}$, arterial oxygen tension; $\mathrm{PCO}_{2}$, arterial carbon dioxide tension; Hct, hematocrit. ${ }^{*} \mathrm{P}<0.01$, compared to the vehicle administered group, ${ }^{\#} \mathrm{P}<0.01$, compared to the baseline value (Wilcoxon's $U$-test). 


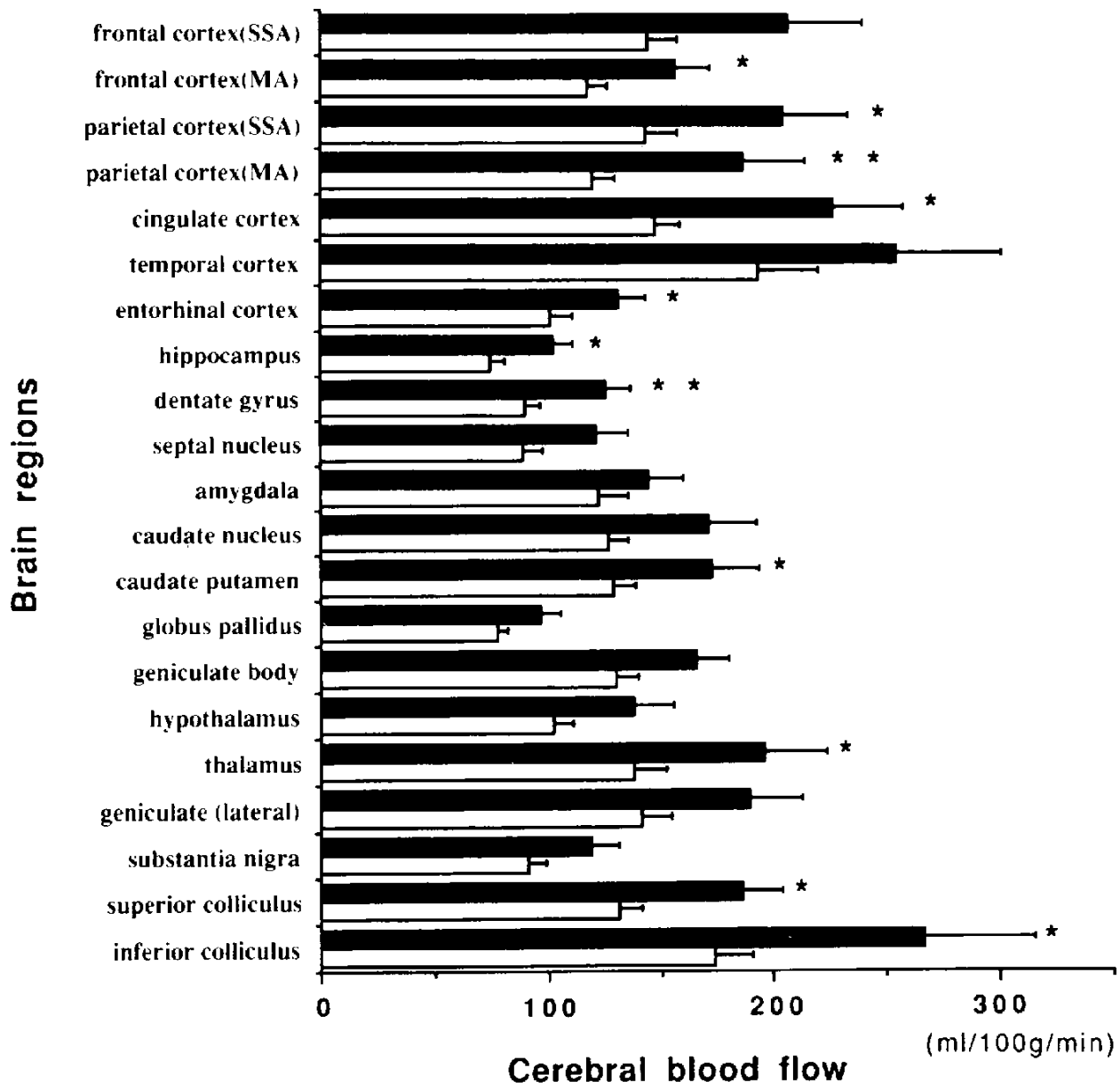

Fig. 1. The effect of nilvadipine on local cerebral blood flow at the time of 15 min aftcr administration in rats. Drug was administered intravenously. The white and solid columns represent brain regions after vehiclc and nilvadipine treatment, respectively. SSA indicates the somatosensory area and MA indicates motor area. Values are means \pm S.E. of 11 experiments; ${ }^{*} \mathrm{P}<0.05,{ }^{* *} \mathrm{P}<0.01$, as compared to the value in the vehicle-administered group (Wilcoxon's $U$-test).

etal, cingulate cortex by $43.2 \%, 42.7 \%$, $53.4 \%$, respectively, and a smaller increase in the globus pallidus, hippocampus, septal nucleus and substantia nigra by $25.7 \%, 36.6 \%$, $35.5 \%, 30.4 \%$, respectively.

The effects of calcium antagonists on ICBF in intact animals are less clearly established because of the concomitant systemic hypotension. It has been reported that nimodipine given by a continuous intravenous infusion caused significant increases in ICBF in rostral brain areas, but these increases were counteracted by the effect on arterial blood pressure (8). In the present study, we examined the effect of nilvadipine on ICBF.

It has been reported that nilvadipine exhibits a selective effect on cerebral arteries in vitro $(4,7)$. The $\operatorname{ID}_{50}$ values of nilvadipine for basilar artery contraction induced by $\mathrm{K}^{+}$was lower than those for other arteries. These in vitro data were confirmed by measurement of arterial blood flow in anesthetized dogs using 
an electromagnetic flowmeter method. The increase in vertebral and coronary blood flow was greater than mesenteric, femoral and renal blood flow at doses of $0.32-100 \mu \mathrm{g} / \mathrm{kg}$ nilvadipine (i.v.); and the duration of effect was about two to three times longer than that of nifedipine and nicardipine, an established vasodilator (4). With reference to these data, we selected a dose of $32 \mu \mathrm{g} / \mathrm{kg}$ (i.v.) in the present study. Administration of $32 \mu \mathrm{g} / \mathrm{kg}$ nilvadipine reduced the MABP by $33 \%$. As the systemic hypotension might reduce the $\mathrm{ICBF}$, the effect of drugs on MABP is an important factor when investigating the cerebrovascular effects. In the present study, we found that nilvadipine increased ICBF in all regions in spite of the reduction of MABP 15 min after intravenous injection.

We also found that the action of nilvadipine on the ICBF tended to be more apparent in the cortex than in subcortical regions such as the globus pallidus. Differences in the arterial supply to different brain areas may cause the regional heterogeneity of cerebral blood flow in rat brains (9). These regional heterogeneity may indicate the regional differences of neuronal activity. The mechanism underlying the increase in $\mathrm{ICBF}$ elicited by nilvadipine may involve a dilation of major cerebral arteries, and nilvadipine may thereby cause an increase in collateral blood flow in all regions.

In conclusion, nilvadipine increased ICBF in spite of a reduction in MABP because of its selective action on cerebral arteries under these experimental conditions, thus confirming the effect of nilvadipine on cerebral blood flow (4).

\section{REFERENCES}

1 Fleckenstein, A.: Specific pharmacology of calcium in myocardium, cardiac pacemakers, and vascular smooth muscle. Annu. Rev. Pharmacol. Toxicol. 17, 149-166 (1977)

2 Auer, L.M., Pfurtscheller, G., Abobaker, S., Ott, E., Marguc, K.-J. and Lechner, H.: Penumbra around chronic cerebral infarction? Neurol. Res. 10, 246-251 (1988)

3 Takenaka, T. and Handa, J.: Cerebrovascular effects of YC-93, a new vasodilator, in dogs, monkeys and human patients. Int. J. Clin. Pharmacol. Biopharm. 17, 1-11 (1979)

4 Ohtsuka, M., Ono, T., Hiroi, J., Esumi, K., Kikuchi, H. and Kumada, S.: Comparison of the cardiovascular effect of FR34235, a new dihydropyridine, with other calcium antagonists. J. Cardiovasc. Pharmacol. 5, 1074-1082 (1983)

5 Sakurada, O., Kennedy, C., Jehle, J., Brown, J.D., Carbin, G.L. and Sokoloff, L.: Measurement of local cerebral blood flow with iodo$\left[{ }^{14}\right.$ Clantipyrine. Am. J. Physiol. 234, H59-H66 (1978)

6 Palkovits, M. and Brownstein, M.J.: Maps and Guide to Microdissection of the Rat Brain. Elsevier Science Publishing Co., Inc., New York (1988)

7 Takagi, T., Satake, N. and Shibata, S.: The inhibitory action of FR34235 (a new $\mathrm{Ca}^{2+}$ entry blocker) as compared to nimodipine and nifedipine on the contractile response to norepinephrine, potassium and 5-hydroxytryptamine in rabbit basilar artery. Eur. J. Pharmacol. 90, 297 - 299 (1983)

8 Mohamed, A.A., McCulloch, J., Mendelow, A.D., Teasdale, G.M. and Harper, A.M.: Effect of the calcium antagonist nimodipine on local cerebral blood flow: relationship to arterial blood pressure. J. Cereb. Blood Flow Metab. 4, 206211 (1984)

9 Bär, T. and Scheck, T.: The vascular system of the rat cerebral cortex-Basic pattern of leptomeningeal vessels and numerical densities of neocortical arteries and veins. In The Cerebral Veins. An Experimental and Clinical Update, Edited by Auer, L.M. and Loew, F., p. 65-71, Springer, New York (1983) 